\title{
Technical Challenges Associated with the Integration of Wind Power into Power Systems
}

\author{
Pavlos S. Georgilakis, Member, IEEE, Nikos D. Hatziargyriou, Senior Member, IEEE
}

\begin{abstract}
Wind power is going through a very rapid development. It is the fastest growing power source in the world, the technology is being developed rapidly and wind power is supplying significant shares of the energy in large regions. The integration of wind power in the power system is now an issue in order to optimize the utilization of the resource and in order to continue the high rate of installation of wind generating capacity, which is necessary in order to achieve the goals of sustainability and security of supply. This paper presents the main technical challenges that are associated with the integration of wind power into power systems. These challenges include effects of wind power on the power system, the power system operating cost, power quality, power imbalances, power system dynamics, and impacts on transmission planning. In addition, the paper presents the technology and expectations of wind forecasting as well as cases where wind power curtailment could arise. Future research directions for a better understanding of the factors influencing the increased integration of wind power into power systems are also provided.
\end{abstract}

Index Terms-Grid integration, power imbalances, power quality, power system dynamics, power system operating costs, power system operation, transmission planning, wind forecasting, wind power, wind power curtailment.

\section{INTRODUCTION}

$\mathrm{G}^{2}$ RID integration concerns have come to the fore in recent years as wind power penetration levels have increased in a number of countries as an issue that may impede the widespread deployment of wind power systems. Two of the strongest challenges to wind power's future prospects are the problems of wind intermittency and grid reliability.

The conventional management of transmission and distribution operation is challenged by electricity market restructuring, security of supply concerns and the integration of newer generation technologies such as wind power.

Transmission availability can be a barrier to wind power development. Favorable wind locations are often in areas distant from existing transmission. Building new transmission lines can be difficult due to planning barriers, land use rights and costs.

Internationally accepted standards for power

This work was supported in part by the European Commission under VBPC-RES project contract number FP6-INCO-CT-2004-509205.

P. S. Georgilakis is with the Department of Production Engineering and Management, Technical University of Crete, Chania, Greece, (e-mail: pgeorg@dpem.tuc.gr).

N. D. Hatziargyriou is with the School of Electrical and Computer Engineering, National Technical University of Athens, Athens, Greece, (email: nh@mail.ntua.gr). performance, safety, noise and other environmental-related conditions are needed to reduce market barriers, as well as administrative and installation costs.

This paper presents the main technical challenges that are associated with the integration of wind power into power systems. These challenges include effects of wind power on the power system, the power system operating cost, power quality, power imbalances, power system dynamics, and impacts on transmission planning.

The paper is organized as follows: Section II presents the effects of wind power on the power system. Section III quantifies the wind power impacts on electric power system operating costs. Sections IV, V, VI, and VII present the effects of wind power on power quality, power imbalances, power system dynamics, and transmission planning, respectively. Section VIII presents the technology and expectations of wind forecasting and Section IX describes cases where wind power curtailment could arise. Section $\mathrm{X}$ provides future research directions for a better understanding of the factors influencing the increased integration of wind power into power systems. Section XI concludes the paper.

\section{EFFECTS OF WIND POWER ON THE POWER SYSTEM}

Regarding the power system, the drawbacks of wind power are that wind power production is variable, difficult to predict and cannot be taken as given. However, integration of variable sources is much less complicated if they are connected to large power systems, which can take advantage of the natural diversity of variable sources. A large geographical spreading of wind power will reduce variability, increase predictability and decrease occasions of near-zero or peak output. The power system has flexible mechanisms to follow the varying load that cannot always be accurately predicted. As no production unit is $100 \%$ reliable, part of the production can come from variable sources, with a similar risk level for the power system.

Power system size, generation capacity mix (inherent flexibility) and load variations have an effect on how intermittent production is assimilated into the system. If the proportion of intermittent power production is small and if wind power production is well dispersed over a large area and correlates with the load then wind power is easier to integrate into the system.

In short term, mainly the variations in wind power production affect power system operation. This refers to the allocation and use of extra reserves as well as cyclic losses of conventional power production units, and transmission or distribution network impacts. The area we have to look at for intra-hour variations is the synchronously operated 
system. In a large system, the reserve requirements of different loads and wind power interact and partly compensate each other. The power system operation then needs only to balance the resulting net regulation. The variability introduced by wind power will not be significant until variations are of the same order as the variability of the random behavior of electricity consumers. On the time scale of seconds and minutes (primary control), the estimates for increased reserve requirement have resulted in a very small impact. On the time scale of 15 minutes to 1 hour, the estimated increase in reserve requirement is of the order of $2-10 \%$ of installed wind power capacity, when the wind energy penetration level is $10 \%$ [1].

In long-term, the expected wind power production at peak load hours has an impact on the power system adequacy. It is expressed as the capacity credit of wind power. For a low system penetration, the capacity credit equals that of a completely reliable plant generating the same average power at times when the system could be at risk. As the penetration increases, variable sources become progressively less valuable for saving thermal capacity.

There are no technical limits to the integration of wind power. However, as wind capacity increases, measures have to be taken to ensure that wind power variations do not reduce the reliability of power systems. There will be an increasing economic impact on the operation of a power system if wind power penetration exceeds $10 \%$.

Large-scale wind power still lies in the future for many countries, and there are long-term trends that can influence what impact wind power has on the system, such as the use of electricity for vehicles. At high penetration levels, an optimal system may require changes in the conventional capacity mix.

\section{Wind POWER IMPACTS ON ELECTRIC POWER SYSTEM OPERATING COSTS}

Wind power plants generate electricity when the wind is blowing, and the plant output depends on the wind speed. Wind speeds cannot be predicted with high accuracy over daily periods, and the wind often fluctuates from minute to minute and hour to hour. Consequently, electric utility system planners and operators are concerned that variations in wind plant output may increase the operating costs of the system. This concern arises because the system must maintain balance between the aggregate demand for electric power and the total power generated by all power plants feeding the system. This is a highly sophisticated task that utility operators and automatic controls perform routinely, based on well-known operating characteristics for conventional power plants, sophisticated decision-support algorithms and systems, and a great deal of experience accumulated over many years. In general, the costs associated with maintaining this balance are referred to as ancillary-services costs [2].

System operators are concerned that variations in wind plant output will force the conventional power plants to provide compensating variations to maintain system balance, thus causing the conventional power plants to deviate from operating points that are chosen to minimize the total cost of operating the entire system. The operators concerns are compounded by the fact that conventional power plants are generally under their control and thus are dispatchable, whereas wind plants are controlled instead by nature. Although these are valid concerns, it is important to understand that the key issue is not whether a system with a significant amount of wind capacity can be operated reliably, but rather to what extent the system operating costs are increased by the variability of the wind.

Recently several investigations of wind power impact on electric power system operating costs have been conducted. These studies addressed utility systems with different generating resource mixes and employed different analytical approaches. The common element of the studies is that they seek to determine the cost of ancillary services necessary to accommodate a wind plant on a utility system. There are typically three time scales of interest, which correspond to the operation of the utility system and the structure of the competitive electricity markets:

1. unit-commitment horizon of one day to one week with one hour time increments

2. load-following horizons of one hour with five to ten minute increments (intra-hour)

3. regulation horizon of one minute to one hour with one to five second increments.

TABLE I

WIND IMPACTS ON SYSTEM OPERATING COSTS

\begin{tabular}{|c|c|c|c|c|c|}
\hline \multirow[b]{2}{*}{ Study } & \multirow[b]{2}{*}{$\begin{array}{l}\text { Wind } \\
\text { penetr. } \\
(\%)\end{array}$} & \multicolumn{4}{|c|}{ \$/MWh } \\
\hline & & $\begin{array}{l}\text { Regul } \\
\text { ation }\end{array}$ & $\begin{array}{l}\text { Load } \\
\text { following }\end{array}$ & $\begin{array}{l}\text { Unit } \\
\text { commitme } \\
\text { nt }\end{array}$ & Total \\
\hline UWIG/Xcel [3] & 3.5 & 0 & 0.41 & 1.44 & 1.85 \\
\hline PacificCorp [4] & 20 & 0 & 2.50 & 3.00 & 5.50 \\
\hline BPA [5] & 7 & 0.19 & 0.28 & $1.00-1.80$ & $\begin{array}{l}1.47- \\
2.27\end{array}$ \\
\hline Hirst [6] & $\begin{array}{l}0.06- \\
0.12\end{array}$ & $\begin{array}{l}0.05- \\
0.30\end{array}$ & $0.70-2.80$ & na & na \\
\hline We Energies I [7] & 4 & 1.12 & 0.09 & 0.69 & 1.90 \\
\hline We Energies II [7] & 29 & 1.02 & 0.15 & 1.75 & 2.92 \\
\hline Great River I [8] & 4.3 & & & & 3.19 \\
\hline Great River II [8] & 16.6 & & & & 4.53 \\
\hline CA RPS [9] & 4 & 0.17 & na & na & na \\
\hline
\end{tabular}

na: not available

Each of these time frames has special planning and operating requirements and costs. In the unit-commitment time frame, decisions must be made about which units to start and stop and when to do so to maintain system reliability at minimum cost. The challenge with wind is to do this without knowing precisely the amount and timing of energy production by the wind plant over the day(s)-ahead planning horizon. In the load-following time frame, the challenge is to have adequate reserve capacity available to ramp units up and down to follow the load shape resulting from the random fluctuations in the combined load and wind plant output. In the regulation or load-frequency-control time frame, sufficient regulating capacity must be available from the units on regulating duty to hold deviations within the prescribed tolerances.

A summary of the results of the recent studies [3-9] is provided in Table I. It is concluded that the operating cost 
impacts are small at low penetration levels and moderate at higher penetration levels.

\section{POWER Quality}

The location and intermittent nature of wind turbine machines can cause power quality problems such as voltage dips, frequency variations, and low power factor. Wind turbines, especially inductive machines, tend to absorb reactive power from the system and produce a low power factor. If wind turbines absorb too much reactive power, the system can become unstable.

Poor power quality can cause the end user's equipment to operate inefficiently, i.e. lights to flicker, or the utility system becomes unstable and disrupts power to the customer. Power quality problems caused by wind power are best solved at the point of interconnection of the wind generator to the utility grid [10]. New state-of-the-art wind generators utilize power electronics and variable-pitch turbines that allow the wind turbine to produce energy at various wind speeds [11]. The same power electronics regulate the turbine's output voltage while keeping the power factor close to unity. The power electronics in the turbine control the voltage and phase angles of the rotor's currents to control the output voltage and power factor. In the past, utilities relied on switched capacitors to keep the voltage steady and maintain power factor. However, switching capacitors could only provide fixed amounts of volt-ampere reactive (VARs) and tended to put stress on the wind turbine's gearbox and increase its cost of maintenance. The power electronics in new wind turbines provide the appropriate amount of VARs without stressing the wind turbine gearboxes. In addition to adding power electronics inside the wind turbines, some utilities are looking to DC and voltage source converter (VSC) to connect the wind turbines to their grid to stabilize the voltage and frequency.

\section{POWER IMBALANCES}

Many utilities are concerned that wind power may cause power flow imbalances on their systems. They are concerned about the perceived unpredictability of wind. Wind could blow when the load requirements are low. This could cause too much power to flow on a utility's system. They would have to then shut down the wind power and thus lose its benefits. On the other hand, when they need the output from the wind generators the wind may not be blowing.

Some utilities charge an extra imbalance penalty. For example, the Bonneville Power Administration (BPA) used to charge all generators, including wind developers, \$100 per megawatthour when they failed to deliver scheduled power over the transmission grid and caused power imbalances. Wind developers expressed their objections to this charge. In order to encourage wind development in the BPA service territory, BPA decided in 2002 to stop charging wind developers the power flow imbalance penalty. The Federal Energy Regulatory Commission (FERC) approved the removal of the penalty [12].

Eltra, the utility serving western Denmark, has the largest penetration of wind power in the world as compared to the size of its power system. Eltra has conducted a series of simulation studies on power imbalances and possible power quality problems caused by integrating wind power into the grid. These studies have shown that Eltra will have to look new ways to handle excess generation when wind generation exceeds the load requirements of western Denmark. Presently, it transmits this excess generation to Norway, Sweden and Germany. In the future, their studies show that Eltra's neighboring systems will not be able to handle the excess generation from wind power. Consequently, Eltra is looking to other solutions, like curtailing wind and local central heating plants and adding flexible loads and heat pumps to its system to reduce the power imbalances.

Riso National Laboratory in collaboration with the Danish electric utilities Eltra, Elsam, and Elkraft recently finished a study on the impact of integrating wind power into the Northern European grid [13]. The study concluded that the present Danish power system capacity may be inadequate and require reinforcement. The Riso National Laboratory study recommended that improving the expected accuracy of prediction of wind power production would increase wind power's market value. It also recommended the introduction of heat pumps and electric cars to the load to help regulate the unpredictability of wind power. Heat pumps could be used when the cost of power is low and the availability of wind power is high. Eltra could use electric vehicle (EV) as an energy storage technology. Typically, EVs charge their batteries at night when the cost of power is low. Consequently, their use increases the flexibility of the power system and allows the increased integration of wind power into the system.

\section{EFFECTS OF Wind POWER ON POWER SysteM DYNAMICS}

Power system dynamics investigates how a power system responds to disturbances that change the system's operating point. Examples of such disturbances are frequency changes because a generator trips or a load is switched in or disconnected; voltage drops due to a fault; changes in prime mover mechanical power or exciter voltage, and so on. The power system is considered stable if the system reaches a new steady state and all generators and loads that were connected to the system before the disturbance are still connected. The original power system is considered unstable if, in the new steady state, loads or generators are disconnected.

The dynamics of a power system are governed mainly by the generators. Thus, if conventional power generation with synchronous generators is on a large scale replaced with wind turbines that use either asynchronous squirrel cage induction generators or variable-speed generation systems with power electronics, the dynamics of the power system will at some point be affected, and perhaps its stability, too.

Although wind turbines indeed affect the transient and small signal dynamics of a power system, power system dynamics and stability are not a principal obstacle to increasing the penetration of wind power. By taking adequate measures, the stability of a power system can be maintained while increasing the wind power penetration.

In the case of constant-speed wind turbines, measures 
must be taken to prevent voltage and rotor speed instability in order to maintain transient stability. This can be done by equipping them with pitch controllers in order to reduce the amount of overspeeding that occurs during a fault; by combining them with a source of reactive power to supply the large amount of reactive power consumed by a squirrel cage generator after a fault, such as a static condenser or static VAR compensator; or by changing the mechanical and/or electrical parameters of the turbine [14]. In the case of variable-speed wind turbines, the sensitivity of the power electronic converter to overcurrents will have to be counteracted in another way than is presently done, namely, by switching off the turbine. However, the literature seems to indicate that there may indeed be other options.

The small signal stability shows that increased levels of wind power penetration do not seem to require any additional measures in order to maintain small signal stability. The generator type that is most likely to engage into power system oscillations is the synchronous generator, and that generator type is not used in the wind turbine types that are presently on the market. Therefore, replacing synchronous generation seems to have either a negligible or a favorable impact on power system oscillations. However, the impact of wind power on the small signal stability of power systems is a rather recent research subject. Hence, results are still very limited. Therefore, the conclusions presented here should be considered preliminary and be used prudently.

\section{TRANSMISSION PLANNING}

Wind turbines are of course mainly installed in places with good wind resources. This can lead to high concentrations of wind power in some regions. This means that large amounts of wind power will be generated in regions where the local consumption is low and the excess has to be exported. In order to do that it is necessary to have a strong transmission grid designed for the transmission of wind power. This basically means that it has the right capacity of power transport from the windy regions to the load centers. This of course is a set of problems that has been known in the past when the transmission grid capacity was designed to fit the needs of power transmission from large central (coal, natural gas or nuclear) power plants. The main problem is the rapid implementation of wind power, which means that the reinforcement of the grid has not been planned and that the procedure for determination of the transmission capacity is different due to the stochastic nature of wind energy. When wind power is going to be exploited at high levels it means that large amounts of power have to be transmitted over long distances and that in the regions with a high wind power production there will be very little if any conventional production. This also has an impact on how inter-area connections are handled with respect to controllability, security of supply of the areas, etc [15].

In most areas of the world with deregulated power markets, existing transmission planning practices do not look ahead towards expanding the transmission grid to serve high wind resources [16]. Individual wind projects cannot afford to pay for major expansion on their own, so the wind resources may remain stranded and underdeveloped.

FERC introduced economic transmission planning, which is planning to build transmission to reduce congestion and not just for reliability purposes [16]. Such economic transmission planning represents an opportunity to access remote wind resources and for this reason the wind industry is keenly interested in it. Yet economic transmission planning faces at least three challenges:

1. Economic transmission planning is viewed separately from transmission planning for reliability, yet the two may be intertwined, i.e., certain reliability fixes may be necessary in order for an economic transmission addition to move forward.

2. These economic transmission studies may not result in any action; market participants are asked, rather than required, as is the case with reliability studies, to contribute financially to support any identified transmission upgrades or expansion.

3. Related to the previous point, economic transmission planning studies are time, labor, and cost intensive, and efforts to keep them going may fail without some sign of success.

\section{WIND FORECASTING}

Wind forecasting is increasingly showing value for the improved scheduling of wind energy and such forecasts can have substantial value even if they are not perfectly accurate [17]. Using physics-based forecasting models, real-time wind and energy data from the wind plants, and computational learning systems such as artificial neural networks or support vector machines, it is possible to provide forecasts of wind energy delivery that are significantly better than simplistic forecasts based on climatology (historic values) or persistence (assuming that what is currently happening will continue without change).

The accuracy of forecast results depends on the specific challenges of the wind plant location, the surrounding terrain, and the local climatology. Because wind plants are internationally located at sites that tend to amplify wind effects when compared with the surrounding space, it is often worthwhile to run customized fine-scale forecasting models and local wind flow models to simulate the enhanced local effects. These results may be combined with other regional forecasts, using computational learning systems to detect complex relationships and optimize the wind energy forecast.

Typically, the operator will want to receive forecasts that run hour-by-hour for the next few days to reduce the unit commitment costs. While results are site-specific, a reasonable expectation at most locations is that the accuracy of the next day hour-by-hour power forecasts using current state-of-the-art methods will have a mean absolute error (MAE) of perhaps $10-15 \%$ of the rated (nameplate) capacity of the wind park.

Notably, the accuracy of energy forecasts (for example, total wind energy for tomorrow) can be significantly better than the accuracy of power forecasts. The exact timing of the passage of weather fronts can be difficult to predict, and because the winds can change with the passage of such 
fronts, errors in timing can result in large power errors. These errors tend to balance out over longer periods of time (several hours or a full day, for example) so the accuracy of energy forecasting can be quite good. This may be useful on systems with substantial gas or hydro generation that have flexibility to reschedule energy delivery over the day.

In addition, forecasting errors are significantly reduced when aggregated on a system-wide basis. Due to the smoothing effects of geographic dispersion, system-wide forecasting errors for multiple dispersed wind plants may be reduced by perhaps $30-50 \%$ when compared with the errors of individual wind plants.

\section{Wind POWER CURTAILMENT}

In most European countries, renewable energy sources have priority access to the grid. In economic terms, wind power should be on top in merit order due to its marginal price of almost zero.

The constraining of wind generation at certain times could reduce the overall system integration costs [18]. Curtailment of wind power production could arise because of network limitations or system aspects.

Examples of wind power curtailment because of network limitations are:

1. Local limitations could give rise to a need to constrain the output of a group of wind generators. The connection of generators is normally planned so that constraints are not required under the conditions covered by the planning criteria. However, conditions not covered by the criteria may arise from time to time.

2. The time frame from application to connection of a wind farm can be down to one year, whereas the time frame from planning to the commissioning of new transmission lines might be a decade.

Examples of wind power curtailment because of system aspects are:

1. At times of low system demand, a minimum level of conventional generation plant must be kept connected to ensure system stability and control, and to ensure that the demand can be met on a day-ahead basis. This is especially a problem in systems dominated by nuclear power due to the high minimum load capability.

2. Due to a risk of a reduction in wind generation output at the same time as rising demand, wind output may have to be constrained to ensure that the load gradient that must be met by the remaining power plants is within their dynamic capacities.

3. In case the nondispatchable generation exceeds demand plus interconnection capacity, the generation surplus must be removed.

4. Modern wind turbines are capable of going from partial load to full power within approximately $10 \mathrm{~s}$, given the necessary wind conditions. This makes wind power a valuable asset for fast regulation.

The risk of curtailment is seen as a barrier to securing financing for future investment in wind generation, so it is important that the level of curtailment is estimated and that the rules and commercial arrangements are in place.

\section{Future Research}

In order to obtain additional important insights that will allow credible estimation of impacts of wind generation at higher penetrations as well as for a wide range of utility systems, important factors to investigate and further explore include:

1. Varying amounts of wind generation. It is clear that the cost of ancillary services increases with increasing wind penetration. A better understanding of this increase for different types of systems and associated mitigation methods should be developed. Nonlinear effects, especially at high penetration levels, should be investigated with system simulation tools.

2. Market structure and imbalance energy pricing. Market-based ancillary-service costs will differ from those provided by a utility in a vertically integrated environment. The availability of a robust hour-ahead market or a well-functioning regional balancing energy market would likely lead to lower cost impacts.

3. Correlation of load and wind forecasting errors. A better understanding of the magnitude and correlation of the respective forecast errors is necessary to generate more accurate results and enable more simplifying assumptions to be made in future analyses.

4. Varying generation portfolio and fuel cost mix. Sensitivity studies need to be conducted on a selected set of representative generation mix scenarios (coal, oil, gas, hydro, nuclear, wind) to enable results to be extrapolated to other utility systems without the need to undertake expensive and time-consuming utility-specific studies.

5. Simplified models and methods. Once a sufficient base of results has been established, correlations among analytical and simulation approaches, trends in results, similarities, and insights should be sought in order to develop simplified approaches and "rules of thumb".

6. Wind penetration definition. A new and more meaningful definition of wind penetration level needs to be developed. The definition needs to change to reflect the changes in the growth and geographical extent of competitive electricity markets and consolidation of control areas. Ancillary services will be drawn from larger market areas with more competition as markets mature.

7. Transmission congestion. We do not have a clear understanding of the impact of transmission congestion on ancillary-services markets as these markets begin to mature. At some point, this is likely to become a limiting factor on the provision of ancillary services for regions with large amounts of wind capacity.

\section{CONCLUSIONS}

The main technical challenges that are associated with the integration of wind power into power systems were 
presented in this paper. These challenges include effects of wind power on the power system, the power system operating cost, power quality, power imbalances, power system dynamics, and impacts on transmission planning.

Work conducted to date shows that wind power's impacts on system operating costs are small at low wind penetrations (about $5 \%$ or less). In most cases, these incremental costs would detract from the value of wind energy on current wholesale markets by $10 \%$ or less. At higher wind penetrations, the impact will be higher, although current results suggest the impact remains moderate with penetrations approaching $20 \%$.

Wind forecasting has substantial value. Its payoff is primarily in the day-ahead time frame through its influence on unit commitment decisions. Most of the value of forecasting is already available through state-of-the-art capabilities. What remains is to integrate these techniques into the day-to-day operation of power systems.

On any given power system, costs arising from wind variability are a strong function of the characteristics of the system, such as generation mix and fuel costs, and will increase with increasing wind penetration, assuming the non-wind characteristics of the system remain unchanged.

\section{ACKNOWLEDGEMENTS}

This work has been performed within the European Commission (EC) funded VBPC-RES project (contract number FP6-INCO-CT-2004-509205). The authors wish to thank the VBPC-RES partners for their contributions and the EC for partially funding this project.

\section{REFERENCES}

[1] T. Ackermann, Wind power in power systems. Chichester: Wiley, 2005.

[2] J. C. Smith, E. A. DeMeo, B. Parsons, M. Milligan, "Wind power impacts on electric power system operating costs: summary and perspective on work to date," presented at the American Wind Energy Association Global WindPower Conference, Chicago, Illinois, March 2004.

[3] D. Brooks, E. Lo, R. Zavadil, S. Santoso, J. Smith, "Characterizing the impact of significant wind generation facilities on bulk power system operations planning,” UWIG, May 2003.

[4] K. Dragoon, M. Milligan, "Assessing wind integration costs with dispatch models: a case study," WindPower2003, Austin, TX.

[5] E. Hirst, "Integrating wind energy with the BPA power system: preliminary study,” Prepared for BPA Power Business Line, Sep. 2002.

[6] E. Hirst, "Integrating wind output with bulk power operations and wholesale electricity markets,” Wind Energy, Vol. 5, No. 1, pp. 19-36, 2002.

[7] Electrotek Concepts Inc, "Systems operations impacts of wind generation integration study,” Prepared for We Energies, June 2003.

[8] GRE Wind Integration Study, presented at UWIG Technical Workshop, Seattle, WA, October 2003.

[9] B. Kirby, M. Milligan, D. Hawkins, Y. Makarov, K. Jackson, H. Shui, "California renewable portfolio standard renewable generation integration cost analysis. Phase 1: One year analysis of existing resources - Results and recommendations,” December 2003.

[10] B. W. Kennedy, "Integrating wind power: transmission and operational impacts,” Refocus, pp. 36-37, January-February 2004.

[11] F. D. Kanellos, N. D. Hatziargyriou, "The effect of variable-speed wind turbines on the operation of weak distribution networks," IEEE Transactions on Energy Conversion, 2002.

[12] Ed Mosey, "Wind farms get a boost from BPA," BPA press release, Portland, Oregon, 2002.

[13] L. H. Nielsen, P. E. Morthorst, K. Skytte, P. H. Jensen, P. Jørgensen, P. B. Eriksen, A. G. Sørensen, F. Nissen, B. Godske, H. Ravn, C. Søndergen, K. Stærkind, J. Havsager, "Wind power in a liberalized
North European electricity exchange,” European Wind Energy conference and exhibition, Nice, France, 1999.

[14] V. Akhamatov, H. Knudsen, A. H. Nielsen, J. K. Pedersen, N. J. Poulsen, "Modelling and transient stability of large wind farms," International Journal of Electrical Power and Energy Systems, Vol. 25, No. 2, pp. 123-144, 2003.

[15] H. Bindner, P. Lundsager, "Integration of wind power in the power system," in Proc. of the $28^{\text {th }}$ Annual Conference of the IEEE Industrial Electronics Society, Vol. 4, pp. 3309-3316, Nov. 2002.

[16] R. Pwiko, D. Osborn, R. Gramlich, G. Jordan, D. Hawkins, K. Porter, "Wind energy delivery issues: transmission planning and competitive electricity market operation,” IEEE Power and Energy, Vol. 3, No. 6, pp. 47-56, Nov/Dec 2005.

[17] M. Ahlstrom, L. Jones, R. Zavadil, W. Grant, "The future of wind forecasting and utility operations: planning for improved system operations," IEEE Power and Energy, Vol. 3, No. 6, pp. 57-64, Nov/Dec 2005

[18] P. B. Eriksen, T. Ackermann, H. Abildgaard, P. Smith, W. Winter, J. R. Grarcía, "System operation with high wind penetration," IEEE Power and Energy, Vol. 3, No. 6, pp. 65-74, Nov/Dec 2005.

\section{BIOGRAPHIES}

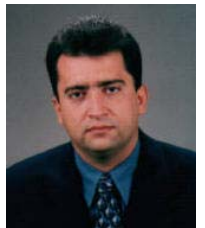

Pavlos S. Georgilakis (S’98, M’01) was born in Chania, Greece in 1967. He received the Diploma in Electrical and Computer Engineering and the Ph.D. degree from the National Technical University of Athens, Greece in 1990 and 2000, respectively. From 1994 to 2003 he was with Schneider Electric AE, where he was $\mathrm{R} \& \mathrm{D}$ manager for three years. He is currently Assistant Professor at the Production Engineering and Management Department of the Technical University of Crete. His research interests include power systems and intelligent systems as well as transformer modeling and design. He is member of IEEE, CIGRE, and the Technical Chamber of Greece.

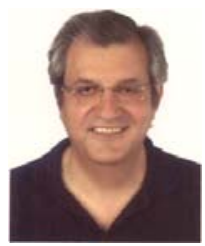

Nikos D. Hatziargyriou (S'80, M'82, SM'90) was born in Athens, Greece, in 1954. He received the Diploma degree in electrical and mechanical engineering from the National Technical University of Athens in 1976, and the M.Sc. and Ph.D. degrees in electrical engineering from the University of Manchester Institute of Science and Technology (UMIST), U.K., in 1979 and 1982, respectively. He is currently Professor in Power Systems at the School of Electrical and Computer Engineering of the National Technical University of Athens. His research interests include dispersed and renewable generation, dynamic security assessment, and application of artificial intelligence techniques to power systems. Prof. Hatziargyriou is the President of IEEE Greek Section, a Senior Member of the Power Engineering Society of IEEE, Greek Member of CIGRE Study Committee C6 "Dispersed Generation" and member of various CIGRE Task Forces and of the Technical Chamber of Greece. 